\title{
Different Flotation Performance of Ultrafine Scheelite under Two Hydrodynamic Cavitation Modes
}

\author{
Weiguang Zhou, Leming Ou *, Qing Shi, Qiming Feng and Hao Chen \\ School of Minerals Processing and Bioengineering, Central South University, Changsha 410083, China; \\ zhouwgcsu@csu.edu.cn (W.Z.); shiqok@csu.edu.cn (Q.S.); Feng_309@csu.edu.cn (Q.F.); \\ 0305110622@csu.edu.cn (H.C.) \\ * Correspondence: olm@csu.edu.cn; Tel.: +86-0731-8883-0913
}

Received: 30 May 2018; Accepted: 16 June 2018; Published: 23 June 2018

\begin{abstract}
In industrial practice, hydrodynamic cavitation (HC) is commonly triggered by jetting either reagent solution or pulp. Although both methods can enhance mineral flotation, are their roles the same? There are few research studies in the field, which severely limits our understanding on mineral flotation combined with HC. Therefore, in this study, the flotation of ultrafine scheelite with HC pretreatments of reagent solution and pulp (abbreviated to be HCPS and HCPP, respectively) was studied and compared through flotation tests, zeta potential analysis, microscope tests, and shear yield stress measurements. The results of flotation tests show that both HCPS and HCPP can enhance the final flotation performance, but in general, HCPP leads to greater improvements on the final flotation recovery. The presence of (hydrophobized) scheelite particles brings extra gas nuclei for the cavitation-flotation system, suggesting that more NBs may be produced in the case of HCPP compared with HCPS. These tiny bubbles remarkably reduce the size distribution of bubbles in the flotation system, thus increasing the particle-bubbles collision probability. Increase in particle aggregation may be another reason why flotation with HCPP results in a higher flotation recovery. The adherence of NBs on hydrophobized particles decreases the (absolute) surface charge of the solids, resulting in a smaller repulsive force among particles and more significant particle aggregation, which is confirmed by the microscope tests and shear yield stress measurements.
\end{abstract}

Keywords: ultrafine scheelite; cavitation mode; nanobubbles; particle aggregation

\section{Introduction}

Scheelite particles are brittle and easily overground in the grind process [1]. As a result, there are always a large number of micro-granular slimes in the scheelite pulp, which weakens the flotation environment and leads to the loss of the valuable minerals [2]. Decreasing the size of flotation bubbles is regarded as an efficient way to recover the fine fractions [3]. In the past two to three decades, a lot of research work has been carried out on the development of air bubbles' sparger design to generate bubbles that are small enough to be used for fine minerals flotation. Luckily, it has been reported that nanoscale bubbles can be produced using a properly designed cavitation Venturi tube in the principle of hydrodynamic cavitation (HC) [4]. More importantly, nanobubbles (NBs), which refer to tiny bubbles that are mostly smaller than a few hundred nanometers, are confirmed to be advantageous to mineral flotation based on theoretical research and industrial practice $[5,6]$.

Due to the high energy efficiency and low maintenance cost, $\mathrm{HC}$ is the mostly commonly used cavitation method, and Venturi tube is the most widely used HC device in flotation field [4]. According to Bernoulli's equation, once the liquid static pressure reduces to the water vapor pressure, cavitation occurs and NBs generates. On the other hand, cavitation inception and the properties of NBs are influenced by many factors, such as liquid velocity, cavitation time, surfactant concentration, particles 
in the bulk, etc. $[7,8]$. There is a liquid threshold for cavitation inception in a Venturi tube. When the liquid velocity exceeds the threshold, the higher the speed, the more pronounced the cavitation phenomenon will be [9]. Xiong [10] has discovered that it takes a certain time to generate sufficient NBs in the aqueous solution during the cavitation process. The presence of surfactant does not reduce the cavitation threshold, but contributes to the production of more stable and smaller NBs in the solution [11]. Furthermore, it has been announced that the effect of particles on HC depends on particle surface properties. Specifically, hydrophilic particles have little impact on cavitation inception, while hydrophobic (hydrophobized) particles can act as nuclei, making cavitation more prone to occur [12].

In mineral flotation, $\mathrm{HC}$ can be induced either by $\mathrm{HC}$ pretreatments of reagent solution (HCPS) [13] or by HC pretreatments of pulp (HCPP) [14]. In particular, HCPS refers to the cavitation triggered by chemical reagent solution passing through the Venturi tube at a high speed, while HCPP means the cavitation incepted by flotation pulp passing through the Venturi tube at a high speed. Studies have shown that NBs generated in the process of HCPS and HCPP can selectively adsorb on the hydrophobic particle surfaces, promote the aggregation of dispersed particles, and meanwhile serve as the nuclei for flotation bubbles attachment, thus enhancing the flotation of ultrafine minerals flotation [15]. However, the cavitation performance and bubble-particle interaction are largely different in the absence and presence of particles during cavitation. In the flotation with HCPS, NBs are usually produced firstly in the bulk (i.e., bulk nanobubbles, BNBs) and adsorb onto the hydrophobic mineral surfaces as a second step. In the flotation with HCPP, hydrophilic particles have little effect on the initial cavitation; NBs produced mainly BNBs in this case. As the content of hydrophobic particles increases, or the hydrophobicity of mineral surfaces increases, NBs tend to nucleate at the mineral surfaces directly, forming surface NBs (i.e., SNBs) due to the smaller adhesion work between solid particles and water compared with water cohesion work. Therefore, all of the factors that affect the hydrophobicity of the mineral surface can affect the formation of SNBs. Compared with flotation assisted by HCPS, ultrafine particles can attach to NBs without the need of particle-bubble collision in the case of HCPP, which has been proved to be the rate-determining step in froth flotation for ultrafine particles [16]. These will bring about significant differences in the NBs' adhesion onto the mineral surface and particle aggregation, which therefore lead to differing flotation environment and final flotation responses [17,18].

Much progress has been reported in the last decade for the research, development, and application of HCPS or HCPP and associated NBs in mineral flotation. Specifically, a lot of studies about the application of HCPS and HCPP on mineral flotation have been carried out in the flotation of coal, phosphate, oil sands, etc. [10]. However, few research studies have been done to compare the flotation performances under these two cavitation modes. To reveal the different flotation responses, the flotation of ultrafine scheelite particles with HCPS and HCPP was compared in this study. The reasons for the differences in flotation behaviors was further analyzed from the perspective of NBs and their roles in particle aggregation.

\section{Materials and Methods}

\subsection{Materials and Reagents}

The scheelite sample was obtained from Yuanling, Hunan Province, China. After handpicking, the sample was crushed and dry ground in a ceramic ball mill, then elutriated to collect the $-10 \mu \mathrm{m}$ size fraction for flotation tests, and $-2 \mu \mathrm{m}$ size fraction for zeta potential measurements. The particle size distribution has already shown in our published paper [19]. The samples were analyzed via a chemical method, showing that the content of $\mathrm{WO}_{3}$ was $80.24 \%$. The XRD of the sample was shown in Figure 1, which revealed that the sample was of high purity (99.64\%). Sodium oleate (NaOl, AR) was used as the collector in this study. $\mathrm{HCl}$ and $\mathrm{NaOH}$ acted as $\mathrm{pH}$ modifiers. Deionized and double distilled water was used for all of the experiments. 


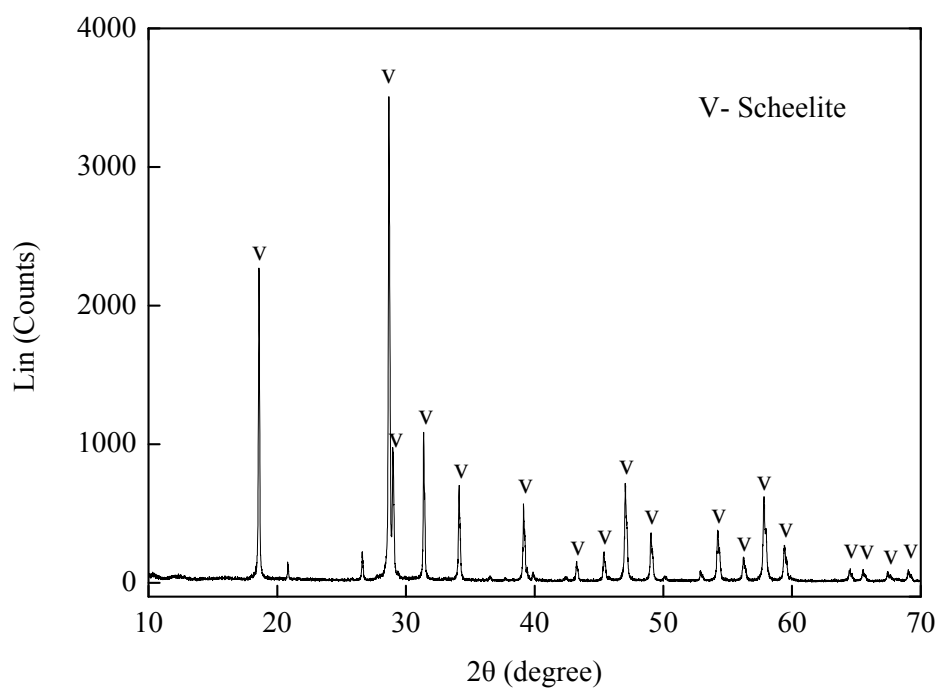

Figure 1. XRD of scheelite.

\subsection{NBs Generation and Characterization}

The NBs generation/cavitation-flotation system used in this study was the same as that shown in a previous study, and all the devices are of the same specifications as the previous ones as well [19]. First, $100 \mathrm{~mL}$ of solution with a $\mathrm{pH}$ value of 10 and a certain concentration of $\mathrm{NaOl}$ was pumped through a centrifugal pump into a Venturi tube. In order to produce enough NBs for subsequent experiments, we kept the cavitation time as $10 \mathrm{~min}$. When the air-saturated solution reached the throat of the Venturi tube, the solution was depressurized, and cavitation was triggered. As a result, the NBs were formed in the bulk solution. After $10 \mathrm{~min}$ of cavitation processing, solution containing NBs were transferred to measure the size distribution of NBs, or a flotation cell of XFG laboratory flotation machine (Jilin exploration machinery factory, Changchun, China) for flotation tests.

The size distribution of NBs generated in the bulk solution was measured through a ZetaSizer Nano ZS 90 instrument (Malvern instruments Ltd., Worcestershire, UK), based on the DLS technique. Average diameter, $\mathrm{Db}(0.5)$, was used as instrument output to characterize the NBs' size. Size measurement was conducted at $20^{\circ} \mathrm{C}$ three times, and the average was reported as the final value.

\subsection{Flotation Tests}

Before we launched the flotation tests in the 100-mL flotation cell, the pulp was preconditioned in the "Reactor" under two different approaches:

(1) HCPS. In the absence of mineral particles, $100 \mathrm{~mL}$ of $\mathrm{NaOl}$ solution was firstly conditioned in the Reactor for $10 \mathrm{~min}$. Then, $4 \mathrm{~g}$ of scheelite and $96 \mathrm{~mL}$ of pretreated $\mathrm{NaOl}$ solution were added into the flotation cell together to make the flotation pulp.

(2) HCPP. With a given concentration of $\mathrm{NaOl}, 4 \mathrm{~g}$ of scheelite and $96 \mathrm{~mL}$ of solution were mixed well in the Conditioning tank, firstly. Then, the mineral suspension was injected into the Reactor for cavitation treatment for $10 \mathrm{~min}$. After that, the suspension was transferred into the flotation cell to make the flotation pulp.

Although the residence time of solids in the case of HCPP is 10 min longer than that of HCPS in the solution containing NBs, we explored and found that its influence on final flotation recovery was just minor. Firstly, the well-conditioned flotation pulp was conditioned for 3 min in the flotation cell. The final flotation was performed for $5 \mathrm{~min}$. The floated and unfloated particles were collected, filtered, and dried subsequently. The flotation recovery was calculated based on solid mass distributions between the two products. Each microflotation test was implemented three times, and the average was regarded as the final values. 


\subsection{Zeta-Potential Measurements}

The zeta potential of scheelite as a function of $\mathrm{pH}$ was measured under different conditions by the same ZetaSizer Nano ZS instrument (Malvern instruments Ltd., Worcestershire, UK) mentioned in Section 2.2. $\mathrm{KCl}(0.01 \mathrm{~mol} / \mathrm{L})$ was used as the background electrolyte. Before the final measurement, the mineral suspension was stirred for $3 \mathrm{~min}$ using a magnetic stirrer and subject to $10 \mathrm{~min}$ of standing, so that few free bubbles existed in the suspension (except for NBs). Each data point for zeta potential was an average of three measurements and carried out at $20^{\circ} \mathrm{C}$. Suspension with a high zeta potential is electrically stabilized, while suspension with a low zeta potential tends to aggregate.

\subsection{Microscope Tests}

Microscope tests were performed to unveil the particle dispersion/aggregation state in the cases of HCPS and HCPP. The procedure of preparing the target mineral suspensions was almost the same as that shown in Section 2.2, except changing the weight of scheelite added from $4 \mathrm{~g}$ to $0.5 \mathrm{~g}$ at the beginning of mineral suspension preparation. After cavitation treatment, the mineral suspension was well mixed for $3 \mathrm{~min}$ in a beaker gently so that no extra large bubbles formed in this period. The mineral suspension was transferred into a colorimeter tube and settled for $20 \mathrm{~min}$, after which a drop of supernatant liquor of fixed height $(2 \mathrm{~cm})$ was extracted out for image analysis. As NBs are of incredible stability in water media, and with a relatively slow setting rate, these operations help to reduce the interference caused by the excessive solids for the latter observation. The observation was finally fulfilled using an optical microscope (Olympus-Cx31rts, Olympus corporation, Tokyo, Japan).

\subsection{Shear Yield Stress Measurements}

In flotation, pulp rheology is a sensitive indicator of the state of aggregation/dispersion of mineral particles [20]. Shear yield stress is a measure of the resistance of the floc to the permanent deformation in shear, or the minimum stress needed for the occurrence of flow [21]. The yield stress of the flotation pulp has been proven to be useful in characterizing the particle aggregation degree in the pulp [22]. In this study, the yield stress measurement was conducted with a rheometer (Anton Paar MCR102, Anton-Paar Ltd., Graz, Austria) and a vane impeller probe. First, $40 \mathrm{~mL}$ of mineral pulp was pretreated as the conditioning operations stated in Section 2.3, after which the well-conditioned pulp was transferred into the sample holder for the measurement. The shear stress sweep ranged from $0.01 \mathrm{~Pa}$ to $10 \mathrm{~Pa}$ within six min to fulfill the stress range. Yield stress was acquired from the shear stress versus shear strain curves where shear strain suddenly increased as shear stress increased. It was calculated by the point where the tangent lines of the strain curves intersected. More details of the measurement procedures can also be seen in Zhang [23].

\section{Results and Discussion}

\subsection{Ultrafine Scheelite Particles Flotation with HCPS and HCPP}

Figure 2 demonstrates the results of the flotation recovery of ultrafine scheelite particles as a function of solution $\mathrm{pH}$ under different conditions. Noticeably, both HCPS and HCPP lead to higher flotation recoveries at the same $\mathrm{pH}$ conditions, confirming that $\mathrm{HC}$ enhances the flotation of ultrafine particles. Compared with HCPS, HCPP promotes the flotation recovery more significantly, especially under intermediately and weakly alkaline conditions $(\mathrm{pH} 8-10)$. This may be related to the surface hydrophobicity of scheelite in $\mathrm{NaOl}$ solution. Under acidic conditions, the adsorption of $\mathrm{NaOl}$ on scheelite is so weak that the surface of scheelite is not hydrophobic enough. The relatively hydrophilic particles have little effect on cavitation, resulting in similar cavitation and flotation performances in the cases of HCPS and HCPP. As pH increases (e.g., pH 8-10), the chemisorption of $\mathrm{NaOl}$ on scheelite significantly improves the surface hydrophobicity of scheelite [24], which therefore promotes the cavitation and NBs formation in the process of HCPP. In addition, when the $\mathrm{pH}$ of pulp is high (e.g., above 10), the effect of HCPS on enhancing ultra-fine scheelite particles flotation seems to be 
weaken, which may be mainly attributed to the increased foaming ability of $\mathrm{NaOl}$ and associated entrainment [25].

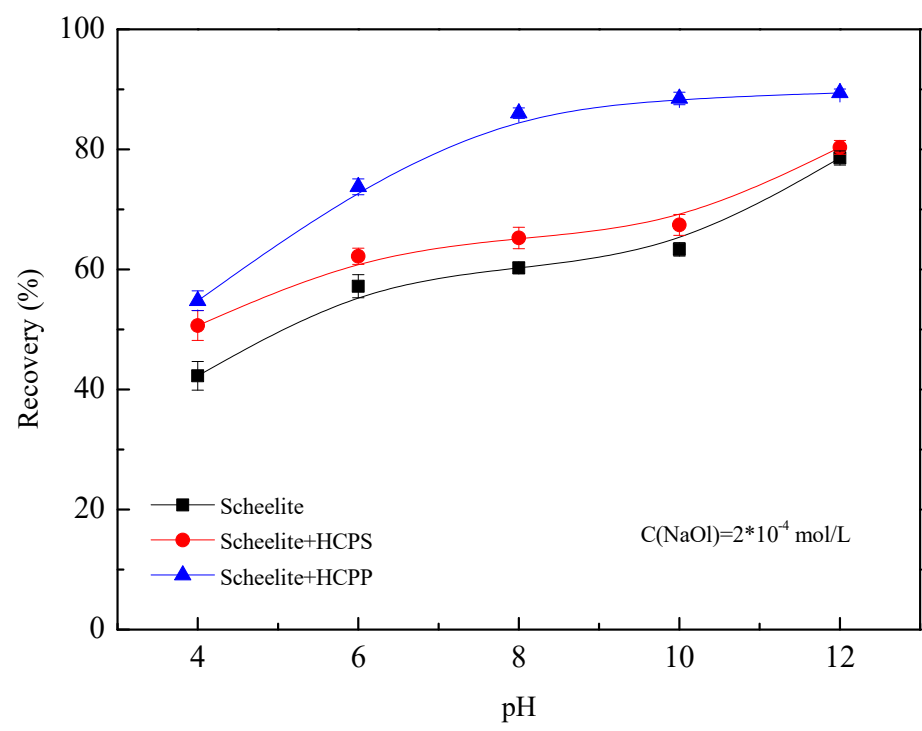

Figure 2. Flotation recovery of ultrafine scheelite with hydrodynamic cavitation (HC) treatments as a function of $\mathrm{pH}$.

Figure 3 shows the comparative results of the flotation recovery of ultrafine scheelite particles as a function of $\mathrm{NaOl}$ concentration. It is clear that preconditioning minerals with $\mathrm{HC}$ leads to higher flotation recoveries compared with conventional flotation, which reconfirms that HC can promote the flotation of ultrafine scheelite particles. Under the same $\mathrm{NaOl}$ concentration condition, HCPP promotes the scheelite flotation more noticeably than HCPS. Moreover, the effect of HCPS on improving final flotation recovery gradually decreases as the $\mathrm{NaOl}$ concentration increases, while the enhancement on final recovery is much less affected by $\mathrm{NaOl}$ concentration in the case of HCPP. Based on the statement in Section 1, two different kinds of NBs exist in the solution pretreated by HC. In the case of HCPS, BNBs dominant, while BNBs or SNBs may exist in the case of HCPP, depending on the degree of hydrophobicity of scheelite. The above findings indicate that BNBs and SNBs may play different roles in enhancing the flotation of ultrafine particles.

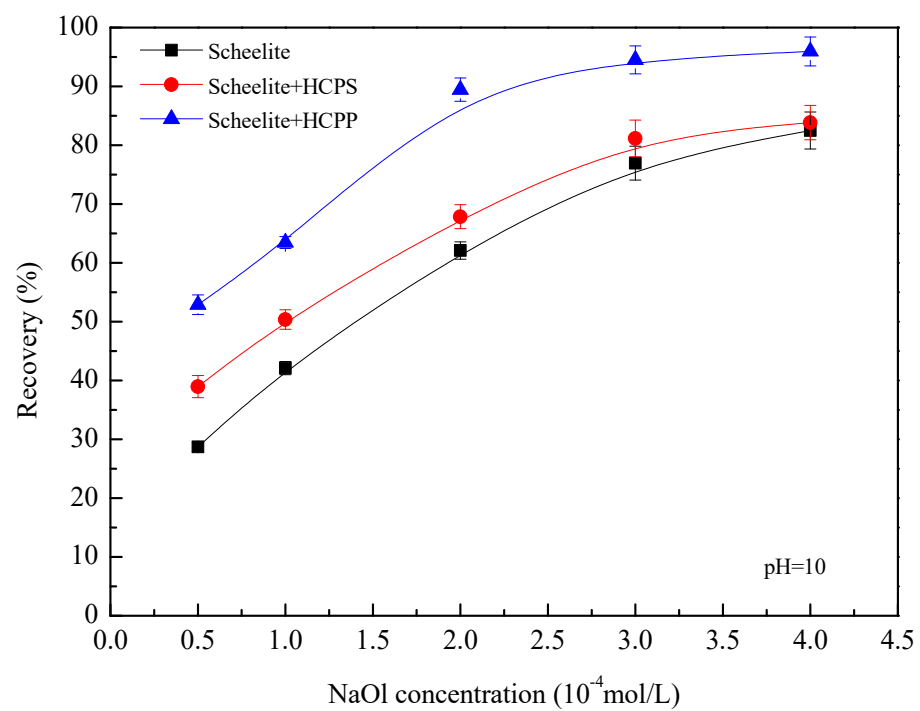

Figure 3. Flotation recovery of ultrafine scheelite with $\mathrm{HC}$ treatments as a function of $\mathrm{NaOl}$ concentration. 
Decreasing bubble size and increasing apparent particle size are the two basic approaches to improving fine and ultrafine mineral flotation [3]. Previous research studies have proven that NBs generated in the process of $\mathrm{HC}$ play roles in both of these two approaches, which are also convinced to be the main contributors for HC-enhanced flotation [26,27]. However, how do NBs affect the bubble average size and particle apparent size in the case of HCPS and HCPP? Considering the different flotation performances revealed above, we will try to clarify the flotation response under different cavitation conditions mainly from these two aspects.

\subsection{NBs Properties and their Influence on Flotation Bubble Size Distribution}

NBs are of incredible stability in aqueous solution, which allows them to remain in water long enough for the non-real-time measurement [28]. In our study, NBs generated by HC are characterized by the average bubble size and average count rate (shown in Figure 4). It is clear that NBs with an average size around $200-300 \mathrm{~nm}$ have been produced in the HC process. Using the same technique, Calgaroto [26] discovered that NBs with a size distribution ranging from $100 \mathrm{~nm}$ to $800 \mathrm{~nm}$ are produced by depressurizing air-saturated water solutions at a high flow velocity. Furthermore, with the increase of $\mathrm{NaOl}$ concentration, the average bubble size decreases and the average count rate increases. Research has shown that the number of tiny bubbles in solution are positively correlated with the value of count rate [29]. It indicates that more and smaller NBs are produced as the concentration of $\mathrm{NaOl}$ increases. With the increasing of $\mathrm{NaOl}$ concentration, the surface tension of solution decreases, benefiting the maintenance of newly generated bubbles by preventing bubbles bursting and coalescence as well [29]. In addition, according to the nuclei theory, there are many gas nuclei stored in the cavities of the particles [30]. It means that the introduction of particles into the aqueous media increases the total gas nuclei of the cavitation system, which therefore promotes the cavitation inception as well as NBs' generation. So, it is demonstrated that many more NBs may be produced in the case of HCPP than HCPS, although the NBs generated by HCPS can hardly characterized due to the presence of solids.

In flotation, these nanoscale bubbles are smaller than conventional-size flotation bubbles for several orders of magnitude in size. The existence of NBs in the pulp significantly reduce the average size of flotation bubbles. As a result, the particle-bubble collision probability, a determining step for ultrafine mineral flotation, can be increased remarkably.

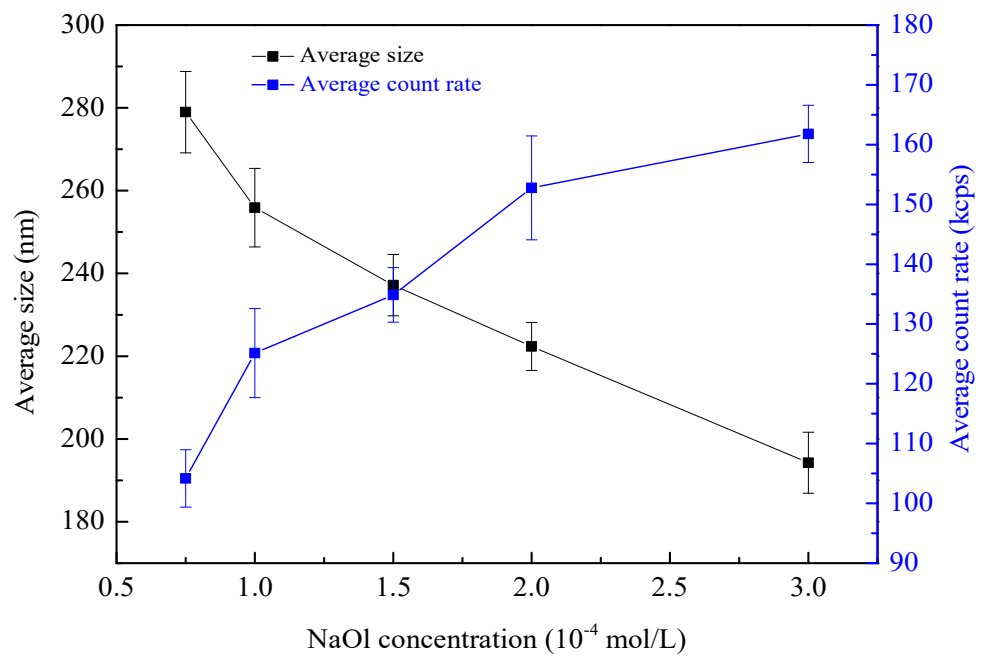

Figure 4. Properties of nanobubbles (NBs) generated by HC.

\subsection{Effect of NBs on Ultrafine Scheelite Particles' Aggregation}

Figure 5 presents the zeta potential of scheelite as a function of $\mathrm{pH}$ under different conditions. It shows that the zeta potential values change to be much smaller after scheelite is treated by $\mathrm{HC}$ in $\mathrm{pH}$ values above 4 . Based on our previous study, the adsorption of NBs generated in the process of $\mathrm{HC}$ on 
the mineral surfaces is the main contributing factor [19]. The mechanism of NBs adhesion leading to the decrease of mineral particles' surface potential is still unclear, with several possible explanations being proposed based on the previous literature [31,32]. Besides, in the case of HCPP, the surface negative potentials of the scheelite particles are significantly reduced, while the zeta potentials of scheelite have smaller changes in the case of HCPS. As we have stated above, SNBs can nucleate on the surface of hydrophobized particles directly in the case of HCPP, while only some BNBs are introduced when HCPS occurs. The zeta potentials results indicate that the attachment of BNBs on hydrophobic surface is much more difficult, compared with the SNBs directly nucleating on the surface with the same hydrophobicity.

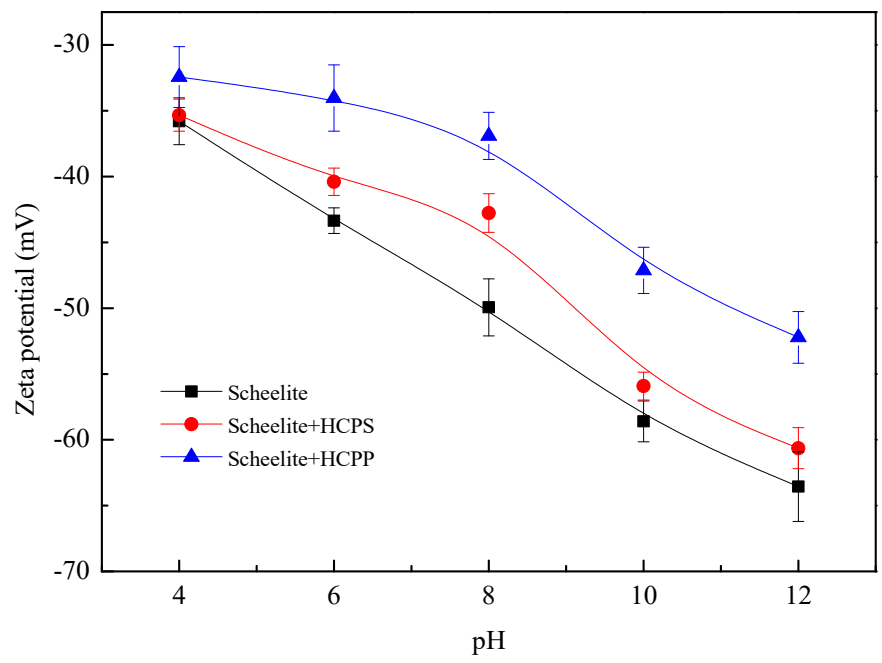

Figure 5. Zeta potentials of scheelite particles with different treatments $\left(\mathrm{C}(\mathrm{NaOl})=2 \times 10^{-4} \mathrm{~mol} / \mathrm{L}\right)$.

Figure 6 indicates the interaction of particles and NBs through photo-micrographs. Generally, NBs generated by HCPS and HCPP are present in the mineral suspension in three states: free nuclei, adhering onto the surface of mineral particles, and forming bubble-particle aggregates. In the mineral suspension with HCPS, NBs are mainly free in the suspension, and particles are basically disperse. In contrast, in the mineral suspension with HCPP, most of NBs mainly adhere onto the surface of the hydrophobized particles or even form large particle-bubble aggregates. The results confirm that SNBs are more likely to adhere onto the hydrophobized particles' surface than BNBs, which is consistent with the data of zeta-potential measurements.

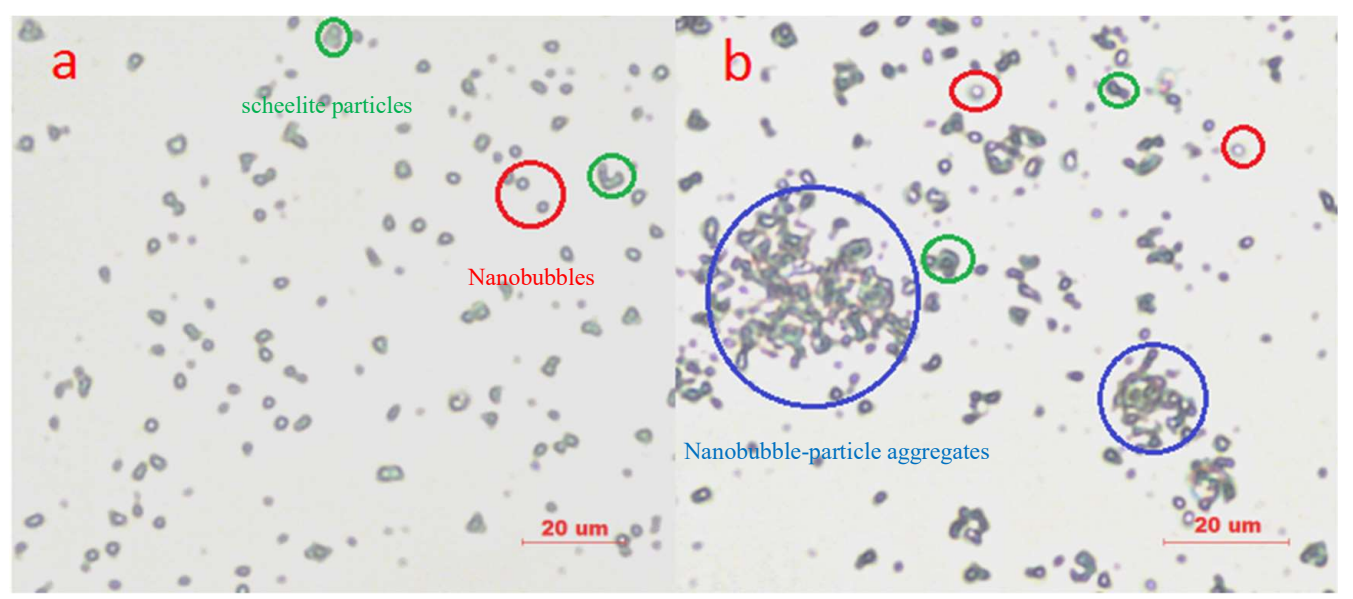

Figure 6. Interaction of particles and NBs under two cavitation treatments ((a): HC pretreatments of reagent solution (HCPS); (b): $\mathrm{HC}$ pretreatments of pulp (HCPP); $\left.\mathrm{C}(\mathrm{NaOl})=2 \times 10^{-4} \mathrm{~mol} / \mathrm{L}\right)$. 
To further clarify the particles' aggregation induced by NBs, the shear yield stress of pulp pretreated in different ways was investigated (shown in Figure 7 and Table 1). Here, $\tau_{0}$ is the shear yield stress, presenting the force needed for breaking the system. It is clear that $\tau_{0}$ is not available in the absence of $\mathrm{NaOl}$ regardless of cavitation pretreatments. It suggests that it is difficult for scheelite particles to form aggregates in the shearing process without $\mathrm{NaOl}$ added. In the presence of $\mathrm{NaOl}$, the shear yield stress of the mineral starts to appear, and increases as the $\mathrm{NaOl}$ concentration increases. When the concentration of $\mathrm{NaOl}$ increases from $2 \times 10^{-5} \mathrm{M}$ to $2 \times 10^{-4} \mathrm{M}$, the shear yield stress of the pulp increases from $0.015 \mathrm{~Pa}$ to $0.092 \mathrm{~Pa}$. It indicates that the addition of $\mathrm{NaOl}$ promotes the aggregation of ultrafine scheelite particles, which has been reported in our previous research [19]. After the scheelite surface is hydrophobized by $\mathrm{NaOl}$, the cavitation pretreatment of pulp contributes to larger shear yield stresses both in the case of HCPS and HCPP. This reconfirms that the NBs generated by HC promote the aggregation of solids. More importantly, compared with the rheological behaviors of scheelite particles under the HCPS and HCPP conditions, it is easy to find that HCPP leads to a greater shear yield stress ( $0.133 \mathrm{~Pa}$ versus $0.102 \mathrm{~Pa}$ and $0.422 \mathrm{~Pa}$ versus $0.369 \mathrm{~Pa}$ ), suggesting that HCPP promotes the aggregation of solids more significantly than HCPS. This finding supports the results shown in microscope tests.

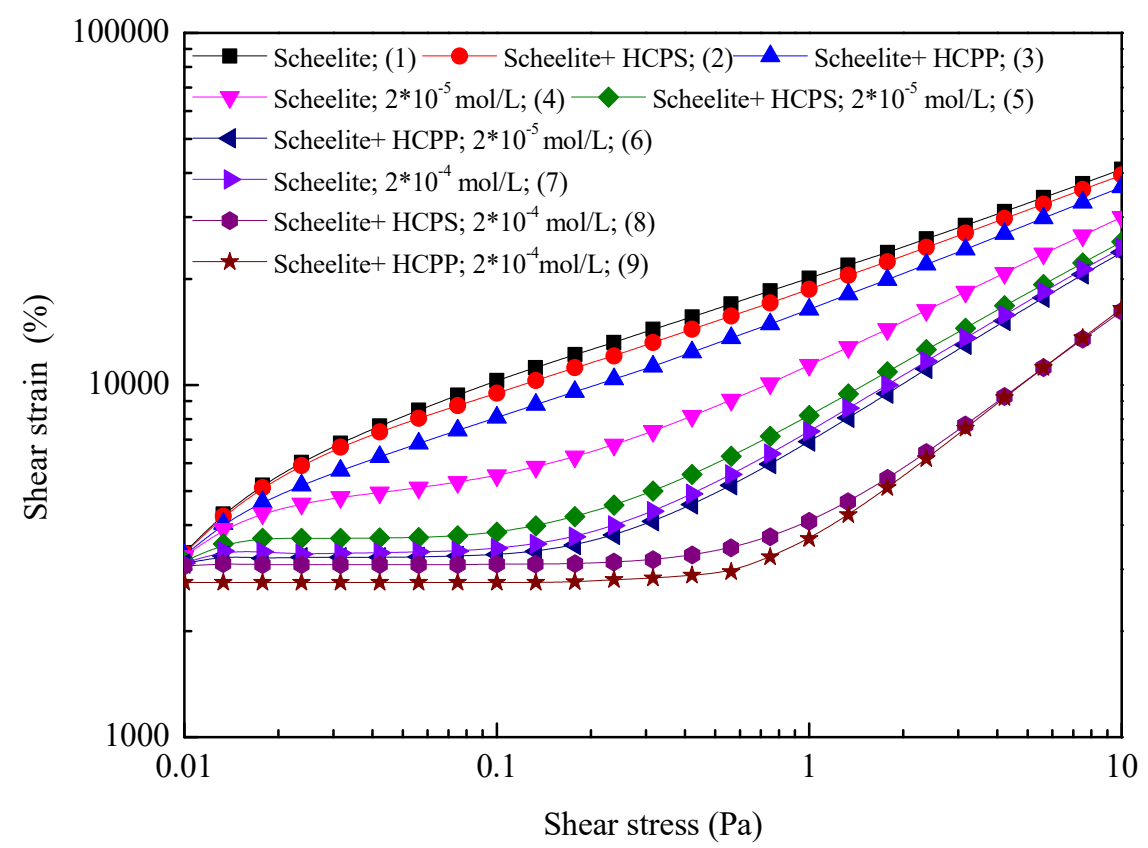

Figure 7. The shear strain of ultrafine scheelite pulp as a function of shear stress under different conditions ( $\mathrm{pH} 10)$.

Table 1. The shear yield stress of scheelite pulp under different conditions.

\begin{tabular}{cccccccccc}
\hline Conditions & $\mathbf{1}$ & $\mathbf{2}$ & $\mathbf{3}$ & $\mathbf{4}$ & $\mathbf{5}$ & $\mathbf{6}$ & $\mathbf{7}$ & $\mathbf{8}$ & $\mathbf{9}$ \\
\hline$\tau_{0}(\mathrm{~Pa})$ & - & - & - & 0.015 & 0.102 & 0.133 & 0.092 & 0.039 & 0.422 \\
\hline
\end{tabular}

In the flotation with HCPS, the generation of NBs decreases the average size distribution of flotation bubbles, therefore increasing the particle-bubble collision probability. Meanwhile, these NBs (i.e., BNBs) also promote the flotation of ultrafine particles to some extent. As a result, the flotation of ultrafine scheelite particles is enhanced. However, as the $\mathrm{NaOl}$ concentration increases, the enhancement of HCPS on the flotation of ultrafine minerals tends to be negligible, suggesting that the enhancement of ultrafine mineral flotation induced by HCPS is limited. In contrast, the improvement on final recovery is more significant in the flotation with HCPP. Initially, more NBs 
are produced, leading to a greater increase in the particle-bubble collision probability. Moreover, the adherence of NBs on hydrophobized particles reduces the surface zeta potentials of particles and promotes the interaction among NBs and ultrafine particles, all of which benefit the particle aggregation. The aggregation of ultrafine scheelite particles in the case of HCPP is more significant, which may be another reason why HCPP results in better flotation performance.

During the experiments, the interaction of NBs and particles is only briefly mentioned, which is a deficiency in our study. Fortunately, some novel techniques have been introduced into this field, such as nanoparticle tracking analysis (NTA) and Atomic Force Microscope (AFM) [33], which provides us chance for further study in the interaction of NBs and mineral particles.

\section{Conclusions}

HC technology applied in mineral flotation can indeed promote the flotation of ultrafine scheelite particles. NBs generated in the HC process, with an average size range from $200 \mathrm{~nm}$ to $300 \mathrm{~nm}$, are attributed to be one of the main contributors. Compared with the flotation with HCPS, flotation with HCPP results in more significant improvement on the final flotation recovery of ultrafine scheelite particles. This is probably because more NBs are generated in the case of HCPP, resulting in higher particle-bubble collision probability. Besides, the aggregation of ultrafine scheelite particles in the case of HCPP is more significant than in the case of HCPS.

Author Contributions: W.Z. and Q.S. conceived of and designed the experiments; W.Z. and H.C. prepared the samples and performed the experiments; W.Z. and L.O. analyzed the data. W.Z., L.O., Q.S., Q.F., H.C. contributed to the writing and revising of the paper.

Funding: This work is financially supported by the Major State Basic Research Development Program of China (973 program) (2014CB643402), the Natural Science Foundation of China (No. 51674291).

Acknowledgments: The authors also thank the support of the Collaborative Innovation Center for Clean and Efficient Utilization of Strategic Metal Mineral Resources.

Conflicts of Interest: The authors declare no conflict of interest.

\section{References}

1. Yin, W.Z.; Wang, J.Z. Effects of particle size and particle interactions on scheelite flotation. Trans. Nonferr. Met. Soc. China 2014, 24, 3682-3687. [CrossRef]

2. Gao, Z.; Bai, D.; Sun, W.; Hu, Y. Selective flotation of scheelite from calcite and fluorite using a collector mixture. Miner. Eng. 2015, 72, 23-26. [CrossRef]

3. Miettinen, T.; Ralston, J.; Fornasiero, D. The limits of fine particle flotation. Miner. Eng. 2010, $23,420-437$. [CrossRef]

4. Fan, M.; Tao, D.; Honaker, R.; Luo, Z. Nanobubble generation and its application in froth flotation (part I): Nanobubble generation and its effects on properties of microbubble and millimeter scale bubble solutions. Min. Sci. Technol. 2010, 20,1-19. [CrossRef]

5. Fan, M.; Tao, D. A study on picobubble enhanced coarse phosphate froth flotation. Sep. Sci. Technol. 2008, 43, 1-10. [CrossRef]

6. Fan, M.; Tao, D.; Honaker, R.; Luo, Z. Nanobubble generation and its applications in froth flotation (part II): Fundamental study and theoretical analysis. Int. J. Min. Sci. Technol. 2010, 20, 159-177. [CrossRef]

7. Zhou, Z.A.; Xu, Z.; Finch, J. On the role of cavitation in particle collection during flotation-A critical review. Miner. Eng. 1994, 7, 1073-1084. [CrossRef]

8. Zhou, Z.A.; Xu, Z.; Finch, J. On the role of cavitation in particle collection during flotation-A critical review II. Miner. Eng. 2009, 22, 419-433. [CrossRef]

9. Li, H.; Afacan, A.; Liu, Q.; Xu, Z. Study interactions between fine particles and micron size bubbles generated by hydrodynamic cavitation. Miner. Eng. 2015, 84, 106-115. [CrossRef]

10. Xiong, Y. Bubble Size Effects in Coal Flotation and Phosphate Reverse Flotation Using a Pico-Nano Bubble Generator; West Virginia University: Morgantown, WV, USA, 2014. 
11. Ahmadi, R.; Khodadadi, D.A.; Abdollahy, M.; Fan, M. Nano-microbubble flotation of fine and ultrafine chalcopyrite particles. Int. J. Min. Sci. Technol. 2014, 24, 559-566. [CrossRef]

12. Zhou, Z.A. Gas Nucleation and Cavitation in Flotation; McGill University: Montreal, QC, Canada, 1996.

13. Calgaroto, S.; Azevedo, A.; Rubio, J. Flotation of quartz particles assisted by nanobubbles. Int. J. Miner. Process. 2015, 137, 64-70. [CrossRef]

14. Fan, M.; Tao, D.; Honaker, R.; Luo, Z. Nanobubble generation and its applications in froth flotation (part IV): Mechanical cells and specially designed column flotation of coal. Int. J. Min. Sci. Technol. 2010, 20, 317-338. [CrossRef]

15. Oliveira, H.; Azevedo, A.; Rubio, J. Nanobubbles generation in a high-rate hydrodynamic cavitation tube. Miner. Eng. 2018, 116, 32-34. [CrossRef]

16. Weber, M.E.; Paddock, D. Interceptional and gravitational collision efficiencies for single collectors at intermediate Reynolds numbers. J. Colloid Interface Sci. 1983, 94, 328-335. [CrossRef]

17. Mishchuk, N.; Ralston, J.; Fornasiero, D. Influence of very small bubbles on particle/bubble heterocoagulation. J. Colloid Interface Sci. 2006, 301, 168-175. [CrossRef] [PubMed]

18. Zhang, M.; Seddon, J.R. Nanobubble-nanoparticle interactions in bulk solutions. Langmuir 2016, 32, 11280-11286. [CrossRef] [PubMed]

19. Zhou, W.; Ou, L.; Shi, Q.; Chen, H. Aggregation of ultra-fine scheelite particles induced by hydrodynamic cavitation. Int. J. Miner. Process. 2016, 157, 236-240. [CrossRef]

20. Genc, A.M.; Kilickaplan, I.; Laskowski, J.S. Effect of pulp rheology on flotation of nickel sulphide ore with fibrous gangue particles. Can. Metall. Q. 2013, 51, 368-375. [CrossRef]

21. Liang, L.; Peng, Y.; Tan, J.; Xie, G. A review of the modern characterization techniques for flocs in mineral processing. Miner. Eng. 2015, 84, 130-144. [CrossRef]

22. Cruz, N.; Peng, Y. Rheology measurements for flotation slurries with high clay contents-A critical review. Miner. Eng. 2016, 98, 137-150. [CrossRef]

23. Zhang, G.; Gao, Y.; Chen, W.; Liu, D. The role of water glass in the flotation separation of fine fluorite from fine quartz. Minerals 2017, 7, 157. [CrossRef]

24. Li, C.; Yongxin, L. Selective flotation of scheelite from calcium minerals with sodium oleate as a collector and phosphates as modifiers. II. The mechanism of the interaction between phosphate modifiers and minerals. Int. J. Miner. Process. 1983, 10, 219-235.

25. Beneventi, D.; Pugh, R.J.; Carre, B.; Gandini, A. Surface rheology and foaming properties of sodium oleate and $\mathrm{C}_{12}(\mathrm{EO})_{6}$ aqueous solutions. J. Colloid Interface Sci. 2003, 268, 221-229. [CrossRef]

26. Calgaroto, S.; Wilberg, K.G.; Rubio, J. On the nanobubbles interfacial properties and future applications in flotation. Miner. Eng. 2014, 60, 33-40. [CrossRef]

27. Gogate, P.R.; Pandit, A.B. A review and assessment of hydrodynamic cavitation as a technology for the future. Ultrason. Sonochem. 2005, 12, 21-27. [CrossRef] [PubMed]

28. Peng, H.; Birkett, G.R.; Nguyen, A.V. Progress on the Surface Nanobubble Story: What is in the bubble? Why does it exist? Adv. Colloid Interface Sci. 2015, 222, 573-580. [CrossRef] [PubMed]

29. Wu, C.; Nesset, K.; Masliyah, J.; Xu, Z. Generation and characterization of submicron size bubbles. Adv. Colloid Interface Sci. 2012, 179-182, 123-132. [CrossRef] [PubMed]

30. Harvey, E.N.; Cooper, K.W.; Whiteley, A.H. Bubble formation from contact of surfaces. J. Am. Chem. Soc. 2002, 68, 2119-2120. [CrossRef]

31. Agarwal, A.; Ng, W.G.; Liu, Y. Principle and applications of microbubble and nanobubble technology for water treatment. Chemosphere 2011, 84, 1175-1180. [CrossRef] [PubMed]

32. Guo, D.; Zhang, X.M.; Dan, C.S.; Wu, F.C. The effect of pressurebased pretreat on the flotation efficiency of coal slurry. J. China Coal Soc. 2011, 36, 1365-1369.

33. Xiao, W.; Ke, S.; Quan, N.; Zhou, L.; Wang, J.; Zhang, L.; Dong, Y.; Qin, W.; Qiu, G.; Hu, J. The role of nanobubbles in the precipitation and recovery of organic-phosphine-containing beneficiation wastewater. Langmuir 2018, 34, 6217-6224. [CrossRef] [PubMed]

(C) 2018 by the authors. Licensee MDPI, Basel, Switzerland. This article is an open access article distributed under the terms and conditions of the Creative Commons Attribution (CC BY) license (http:/ / creativecommons.org/licenses/by/4.0/). 